ORIGINAL ARTICLE

\title{
Nasal patency is related to dust exposure in woodworkers
}

\author{
V Schlünssen, I Schaumburg, N T Andersen, T Sigsgaard, O F Pedersen
}

Occup Environ Med 2002;59:23-29

See end of article for authors' affiliations

....................

Correspondence to: Dr V Schlünssen' Department of

Occupational and

Environmental Medicine,

Skive Hospital, DK 7800,

Skive, Denmark;

vivi_schlünssen@dadlnet.dk

Accepted 12 July 2001

\begin{abstract}
Objectives: A cross sectional study of 54 furniture factories and three control factories was conducted to investigate the relation between subjective and objective nasal obstruction and exposure to wood dust. Methods: Acoustic rhinometry was performed on 161 woodworkers and 19 controls. For each person, four measuring rounds were performed: before work, after 4 hours of work, and after 7 hours of work before and after decongestion. Before the first and third measuring round, each person rated the current feeling of nasal obstruction in the left and right nostril separately, using a visual analogue scale. Personal passive dust measurements were performed on 140 woodworkers.

Results: The mean (SD) of equivalent inhalable dust was relatively low, $1.17(0.62) \mathrm{mg} / \mathrm{m}^{3}$, range $0.17-3.44 \mathrm{mg} / \mathrm{m}^{3}$. The exposure was divided into four levels: controls, low exposure, medium exposure, and high exposure. For the two highest concentrations of exposure, a significant increase in congestion-decreased nasal cavity volume and cross sectional areas-was found after 4 and 7 hours of work, compared with before work. Multivariate linear regression analysis showed positive correlations between concentration of dust and change in mucosal swelling. A significant increase in self rated nasal obstruction was found after work compared with before work for the two highest exposure groups. No correlation between objective nasal variables and self rated nasal obstruction was found. Conclusion: Exposure to wood dust was related in a dose dependent manner to acute nasal obstruction measured by acoustic rhinometry and self reported obstruction, but no correlation was found between measured and self reported obstruction.
\end{abstract}

r he first description of respiratory symptoms among woodworkers was performed by the Italian physician Ramazzini in the 18th century. ${ }^{1}$ Recently, the International Agency for Research on Cancer has classified wood dust as a human carcinogen based on a substantial number of studies from the past 35 years. ${ }^{2}$ Furthermore, wood dust is a well known local irritant, and is often related to a high frequency of nasal complaints, including nasal obstruction..$^{3-11}$ Beside nasal symptoms, nasal patency among woodworkers has been sporadically evaluated by objective methods. Åhman et al have shown deterioration of nasal peak flow during a working week in 39 woodwork teachers but not in 32 controls. They found no impairment in nasal resistance measured by rhinomanometry during a working week in woodworkers or in controls. Wilhelmsson et at ${ }^{4}$ confirmed the sense of nasal obstruction among 50 woodworkers by rhinomanometry, but they did not investigate the relation between concentration of wood dust and nasal patency.

Measurement of nasal patency by acoustic rhinometry ${ }^{12}$ has become more common in recent years. ${ }^{13}$ The method is non-invasive and can be applied to a wider range of subjects than other methods of monitoring the nasal airways, and acoustic rhinometry is at least as sensitive as other methods. ${ }^{14}$

Measurable effects of the degree of nasal mucosal swelling after exposure to dust and volatile organic compounds have previously been demonstrated by acoustic rhinometry. ${ }^{15} 16$

In 1997, we initiated a cross sectional study in Viborg County, Denmark, to investigate the relation between exposure to wood dust and respiratory diseases. ${ }^{17}$

The aim of this paper is to present results on the relation between subjective and objective nasal obstruction and exposure to wood dust.

\section{MATERIAL AND METHODS}

\section{Study design}

One hundred factories in the furniture industry situated in Viborg County in 1997 were identified by means of Statistics
Denmark, the local Danish Working Environment Service, and the local Occupational Health Service. Factories with more than 20 employees were asked to participate ( 45 out of 48 accepted) and additionally a random sample of factories with five to 20 employees participated (nine out of 38). Factories with less than five employees (14) were excluded.

A total of 54 factories participated in the study, and the base study population was defined as all 2381 workers employed in woodworking departments, assembly departments and stock departments of these factories. As a control, 619 people from three factories (two producing refrigerators, one producing hearing aids) with no apparent concomitant air pollution were selected. The 57 factories were visited between October 1997 and June 1998.

For each furniture factory, an average of three people were randomly chosen for nasal investigations. No measurements were performed at four furniture factories because of damaged equipment. Demographic data such as sex, smoking, and age did not differ for the 51 participating factories and the four non-participating factories. From each control factory, six to seven people were randomly chosen for nasal investigations. In total, 161 woodworkers and 19 controls were measured by acoustic rhinometry and by a visual analogue scale of nasal obstruction, and 178 people (159 woodworkers and 19 controls) had valid measurements.

\section{Occupational hygiene survey}

Personal dust sampling that measured the equivalent inhalable and total dust concentration was carried out with passive dust monitors. ${ }^{18}{ }^{19}$ In total 140 of the 159 workers participating in the nasal investigation had a valid dust measurement.

Abbreviations: JEM, job exposure matrix; $A_{\text {min }}$ minimum cross sectional area 
Simultaneously $5 \%$ of the workers performed calibration measurements by inhalable dust sampling (Institute of Occupational Medicine $\left(10 \mathrm{~m}\right.$ ) cassette at $2.0 \mathrm{l} / \mathrm{min}^{20}$ ) and total dust sampling with a $37 \mathrm{~mm}$ Millipore field monitor, closed face, inlet diameter of $5.6 \mathrm{~mm}$ at $1.9 \mathrm{l} / \mathrm{min}$ corresponding to an inlet velocity of $1.25 \mathrm{~m} / \mathrm{s}^{21}$

For each measurement, information about work tasks and type of wood processed was collected. A job exposure matrix (JEM) comprising 18 cells (six different work tasks, three sizes of factories) was created from dust measurements performed in the original study. ${ }^{17}$ This matrix was used to assign a dust value to five people in this study, who had no measurements, but where information about work task was available. For 14 woodworkers no information about level of exposure was available.

\section{Nasal investigations}

The mucosa of the nasal cavity was investigated by acoustic rhinometry. ${ }^{12}$ An audible sound (150-10 000 Hz) generated by a spark propagates through a sound tube into the nasal cavity through the nostril. The sound waves are partly reflected by local change in acoustic impedance due to an alternating cross sectional area. By measuring the signals of the incident and reflected waves in a time domain, it is possible to determine the size of change in the cross sectional area as a function of the distance from the nostril. The size of the minimum cross sectional area $\left(\mathrm{A}_{\min }\right)$ and the areas at 3.3 and $4.1 \mathrm{~cm}\left(\mathrm{~A}_{3.3}\right.$ and $\left.A_{4.1}\right)$ from the nostrils were determined for the two nostrils. By integration of the area-distance curve the nasal volumes $0-5$, $0-7$, and $2-5 \mathrm{~cm}\left(\mathrm{vol}_{0-5}, \mathrm{vol}_{0-7}\right.$, and $\left.\mathrm{vol}_{2-5}\right)$ from the nostrils was determined as well. A nosepiece of the conical type, with either an internal diameter of 8,10 , or $12 \mathrm{~mm}$ was used. The measurements were made under standardised conditionsfor example, at the same time in the respirable cycle (immediately after expiration) and with the person in the sitting position and breathing through the mouth.

For each person, four measuring rounds were performed: $(a)$ before work; $(b)$ after 4 hours of work; $(c)$ after 7 hours of work, before decongestion; and $(d)$ after 7 hours of work, after decongestion.

Decongestion was done with a short acting topical decongestant (zylometazolin, $1 \mathrm{mg} / \mathrm{ml}$ ) sprayed into each nostril 10 minutes before the fourth measurement.

The mean values were calculated from a maximum of three valid measurements on each side of the nose. Curves were manually selected according to Grymer et al. ${ }^{22}$ Immediately before each measuring round, the person's heart rate was noted. Before the first and last measuring round, the room temperature was measured, and the mean daily room temperature was used in the analyses. Before the first and third measuring round (before decongestion), the current feeling of nasal obstruction was rated for each nostril separately, using a visual analogue $10 \mathrm{~cm}$ scale. The scale is a $0-10 \mathrm{~cm}$ line scale labelled no complaints at all $(0)$ at the left end and maximal complaints (10) at the right end. ${ }^{23}$ Data on nasal dimensions and subjective nasal obstruction are presented as the sum of the values from the right and left sides.

\section{Questionnaire}

A modified British Medical Research Council questionnaire ${ }^{24}$ with additional questions on allergy, respiratory symptoms, family history of allergy, rhinitis, smoking, and occupational history including working tasks ${ }^{25}$ were handed out at the factories. Of the 178 people with valid nasal measurements, 166 returned the questionnaire $(93.2 \%)$.

\section{Analysis}

For comparisons of independent data, independent sample $t$ test or one way analysis of variance (ANOVA) was undertaken for normal distributions and the Mann-Whitney test or Kruskal-Wallis test for non-normal distributions. For paired data, paired sample $t$ test was undertaken for normal distributions and the Wilcoxon signed rank test for nonnormal distributions.

Multiple analyses were undertaken with linear regression, and interaction between concentration of dust and smoking and temperature was examined by two way ANOVA. As a confounding control, all models from the start included smoking, age, sex, height, weight, allergy, hay fever, temperature, use of compressed air, use of pine wood, and heart rate before measurement by acoustic rhinometry. Unless otherwise stated, the level of significance was $\mathrm{p}<0.05$.

Unless otherwise stated, the dust exposure was treated as an ordinal scale in the analysis.

\section{RESULTS}

The demographic characteristics of the cohort are listed in table 1 . There were significantly less men in the control group, compared with the woodworkers. No difference in age, smoking, allergy, and hay fever was found in the two groups. Among controls, the mean room temperature was slightly but significantly higher than the mean room temperature among woodworkers.

\section{Occupational hygiene survey}

The aritmetic mean (SD) for the 140 equivalent inhalable dust measurements and the five measurements estimated from the JEM was $1.17(0.62) \mathrm{mg} / \mathrm{m}^{3}$, range $0.17-3.44 \mathrm{mg} / \mathrm{m}^{3}$. The workers were grouped into high $(\mathrm{n}=37)$, medium $(\mathrm{n}=77)$, and low $(\mathrm{n}=31)$ exposure according to the interquartile range of the equivalent inhalable dust concentrations of the total study population, ${ }^{17}$ the medium group contained two quartiles. For 14 woodworkers no information about level of exposure was available.

For 139 woodworkers, the main wood types used were; 51 (37\%) pine wood, 23 (17\%) composite wood (particle board, veneer, medium density fibre board), 11 (8\%) hard wood, and $54(39 \%)$ used mixed wood types. For 20 woodworkers, no information on wood type was obtained. Altogether $45 \%$ used compressed air.

\section{Acoustic rhinometry}

Rhinometric variables for men and women in the first measuring round before work are listed in table $2 . \mathrm{A}_{\min }, \mathrm{vol}_{0-5}$, and $\operatorname{vol}_{0-7}$ were significantly smaller among women than men.

Table 1 Characteristics of the cohort $(n=178)$

\begin{tabular}{lll}
\hline & Woodworkers $(n=159) \dagger$ & Controls $(n=19) \dagger$ \\
\hline Male (n (\%)) & $140(88.1)^{*}$ & $12(63.2)$ \\
Age $(y$, mean (SD)) & $37.2(11.5)$ & $37.1(10.6)$ \\
Current smokers $(\mathrm{n}(\%))$ & $47(32.4)$ & $6(33.3)$ \\
Atopy $(\mathrm{n}(\%)) \ddagger$ & $25(17.0)$ & $2(11.1)$ \\
Self reported hay fever $(\mathrm{n}(\%))$ & $14(9.8)$ & $1(5.9)$ \\
Room temperature $\left({ }^{\circ} \mathrm{C}\right.$, mean $\left.(\mathrm{SD})\right)$ & $22.5(1.74)^{*}$ & $24.3(1.06)$ \\
\hline
\end{tabular}

${ }^{*} p<0.05$ woodworkers $v$ controls; $\uparrow$ Number of valid cases may differ in each variable; $\ddagger$ Defined as ever atopic dermatitis, asthma, or season dependent rhinits. 
Table 2 Nasal parameters before work (measuring round 1) for men and women (sum of right and left side values)

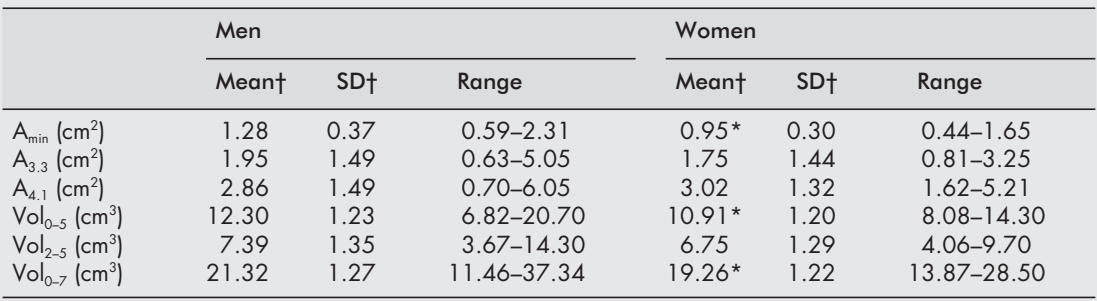

${ }^{*} \mathrm{p}<0.05$ men $v$ women, independent sample $t$ test; $\dagger \mathrm{A}_{\text {min }}$ was normally distributed, consequently the mean (SD) was calculated arithmetically. The other parameters were log normally distributed, consequently the means (SDs) were calculated geometrically.

$\mathrm{A}_{\min }=$ minimum cross sectional area; $\mathrm{A}_{3.3}=$ cross sectional area at $3.3 ; \mathrm{A}_{4.1}=$ cross sectional area at $4.1 \mathrm{~cm}$ vol $_{0-5}=$ volume of the nasal cavity $0-5 \mathrm{~cm} ;$ vol $_{2-5}=$ volume of the nasal cavity $2-5 \mathrm{~cm}$; vol $\mathrm{D}_{-7}=$ volume of the nasal cavity $0-7 \mathrm{~cm}$ from the nostrils among 149 men and 26 women.

Exactly the same pattern was found at 4 and 7 hours (measuring rounds 2 and 3 ).

In the following analysis, the rhinometric variables were adjusted for the effect of decongestion with the formula:

Mucosal swelling $=$ variable $_{4} /$ variable $_{(\mathrm{n})}$

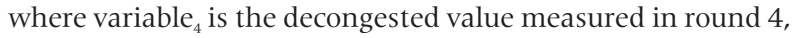
and $n$ is rounds $1-3$. The adjusted variables thus describe the mucosal swelling in rounds 1 to 3 .

Table 3 shows mucosal swelling for nasal volumes and cross sectional areas before work (measuring round 1) for the four exposure groups. No difference was found between the four groups. Exactly the same pattern was found at 4 and 7 hours of work (measuring rounds 2 and 3 ) -that is, no difference between exposure groups was found in the study population.

In figure 1, paired data within the four exposure groups are presented as mucosal swelling ( swell.vol $_{0-5}$, swell.vol $_{2-5}$ ) and nasal cross sectional area (swell. $\mathrm{A}_{4.1}$ ) before work and at 4 and 7 hours of work (measuring rounds 1 to 3 ).

For the two highest levels of exposure, a significant increase in congestion was found at 4 (swell.vol ${ }_{0-5}$, swell.vol ${ }_{2-5}$, swell. $\left.A_{4.1}\right)$ and 7 ( swell.vol $_{0-5,}$, swell.vol ${ }_{2-5}$, swell. $\left._{4.1}\right)$ hours at work, compared with before work. For the low exposure group the same tendency was found, although it was not significant. For the control group, a tendency toward a decrease in congestion was found during the working day.

No difference in congestion during the day for $\mathrm{A}_{\min }$ was found, independent of exposure level (not shown). Swell.vol ${ }_{0-7}$ and swell. $\mathrm{A}_{33}$ showed exactly the same pattern as swell.vol $\mathrm{l}_{0-5}$ and swell. $A_{4,1}$ (not shown). In figure $1 \mathrm{D}, \mathrm{E}$, and $\mathrm{F}$, the percentage of swelling before work was used on the y axis to correct for the pre-exposure level of mucosal swelling. This did not change the tendency towards increasing mucosal swelling during the day for the groups with the highest exposure.
Apparently, there seems to be a dose-dependent change in mucosal swelling during the first 4 hours of working, with no further increase during the rest of the working day.

To investigate the relation between change in congestion and concentration of dust, the difference in congestion between the first and second measuring round was calculated as:

Increase in congestion $=\operatorname{swell}_{(2)} / \operatorname{swell}_{(1)}=\mathrm{D}$

where swell ${ }_{(2)}$ is mucosal swelling measured in round two, and swell $_{(1)}$ mucosal swelling measured in round one.

Table 4 summarises the results of multivariate linear regression analyses of the relations between concentration of dust (categorised in three exposure levels and no exposure) and change in mucosal swelling between the first and second measuring round, including possible confounders, for four nasal variables. Between concentration of dust and all variables, excluding $\mathrm{DA}_{\min }$, positive significant correlations were found. For all volume variables, positive correlations were found for height. For smoking, negative correlations were found for all nasal variables. $\mathrm{Dvol}_{0-7}$ and $\mathrm{DA}_{3.3}$ showed the same pattern as Dvol $_{0-5}$, and $\mathrm{DA}_{4,1}$ (not shown).

No significant interactions were found between smoking and exposure to wood dust or temperature and exposure to wood dust.

The $\mathrm{R}^{2}$ value of the total linear regression model and of a model only including exposure to wood dust is given in table 4. Also, standardised regression coefficients are given. Smoking, heart rate before work, and to a lesser extent height contribute substantially to explain variation in mucosal swelling.

The multivariate linear regression analyses were also performed with the actual environmental dust concentrations in the analysis. The coefficients were nearly identical or

Table 3 Nasal parameters (mucosal swelling) before work (measuring round 1) for four different exposure groups (sum of right and left side values)

\begin{tabular}{lllll}
\hline & $\begin{array}{l}\text { Controls } \\
\mathrm{n}=18\end{array}$ & $\begin{array}{l}\text { Low exposure } \\
\left(0.17-0.74 \mathrm{mg} / \mathrm{m}^{3}\right) \\
\mathrm{n}=30\end{array}$ & $\begin{array}{l}\text { Medium exposure } \\
\left(0.74-1.42 \mathrm{mg} / \mathrm{m}^{3}\right) \\
\mathrm{n}=73\end{array}$ & $\begin{array}{l}\text { High exposure } \\
\left(1.42 \mathrm{mg} / \mathrm{m}^{3}\right) \\
\mathrm{n}=36\end{array}$ \\
\hline Swell.A $\mathrm{A}_{\min }\left(\mathrm{cm}^{2}\right)$ & $0.22 / 0.19(0.27)$ & $0.24 / 0.31(0.28)$ & $0.25 / 0.26(0.28)$ & $0.25 / 0.26(0.22)$ \\
Swell.vol $_{0-5}\left(\mathrm{~cm}^{3}\right)$ & $3.04 / 3.57(2.34)$ & $3.43 / 3.57(1.41)$ & $2.72 / 3.22(2.44)$ & $3.54 / 3.39(1.56)$ \\
Swell. vol $_{2-5}\left(\mathrm{~cm}^{3}\right)$ & $3.05 / 3.40(2.12)$ & $3.21 / 3.27(1.15)$ & $2.57 / 2.98(2.21)$ & $3.42 / 3.15(1.35)$ \\
Swell.vol ${ }_{0-7}\left(\mathrm{~cm}^{3}\right)$ & $6.28 / 6.54(4.35)$ & $6.72 / 6.68(2.40)$ & $5.69 / 6.03(4.80)$ & $6.82 / 6.11(3.23)$ \\
Swell. $A_{3.3}\left(\mathrm{~cm}^{2}\right)$ & $1.03 / 1.14(0.88)$ & $0.94 / 0.96(0.50)$ & $0.78 / 0.91(0.92)$ & $0.82 / 0.84(0.53)$ \\
Swell. $A_{4.1}\left(\mathrm{~cm}^{2}\right)$ & $1.44 / 1.70(1.24)$ & $1.24 / 1.36(0.87)$ & $1.26 / 1.28(1.03)$ & $1.61 / 1.44(0.66)$
\end{tabular}

Swell. $A_{\min }=$ minimum cross sectional area; Swell. $A_{3.3}=$ cross sectional area at $3.3 ;$ Swell. $A_{4.1}=$ cross sectional area at $4.1 \mathrm{~cm}$; Swell.vol ${ }_{0-5}=$ volume of the nasal cavity $0-5 \mathrm{~cm}$; Swell.vol ${ }_{2-5}=$ volume of the nasal cavity $2-5$ $\mathrm{cm}$; Swell.vol $\mathrm{O}_{0-7}=$ volume of the nasal cavity $0-7 \mathrm{~cm}$ from the nostrils, medians/means (SD). 


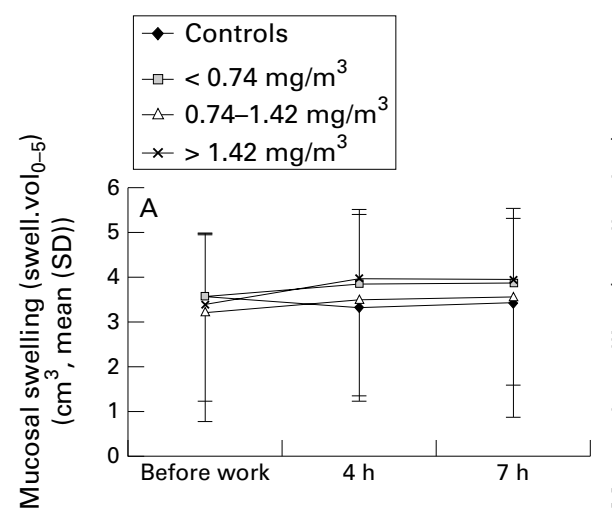

Figure 1 Mucosal swelling (means) in measuring rounds $1-3$ for controls and three exposure levels. In A, B, and $C$ for the two highest exposure levels, a significant increase in congestion was found at 4 and 7 hours at work, compared with before work. (A) swell.vol $0_{0-5}$ (B) swell.vol 2 ; (C) swell. $A_{4.1} ;(D)$ swell.vol ${ }_{0-5} ;(E)$ swell.vol ${ }_{2-5 i}(\mathrm{~F})$ swell. $\mathrm{A}_{4.1}$.
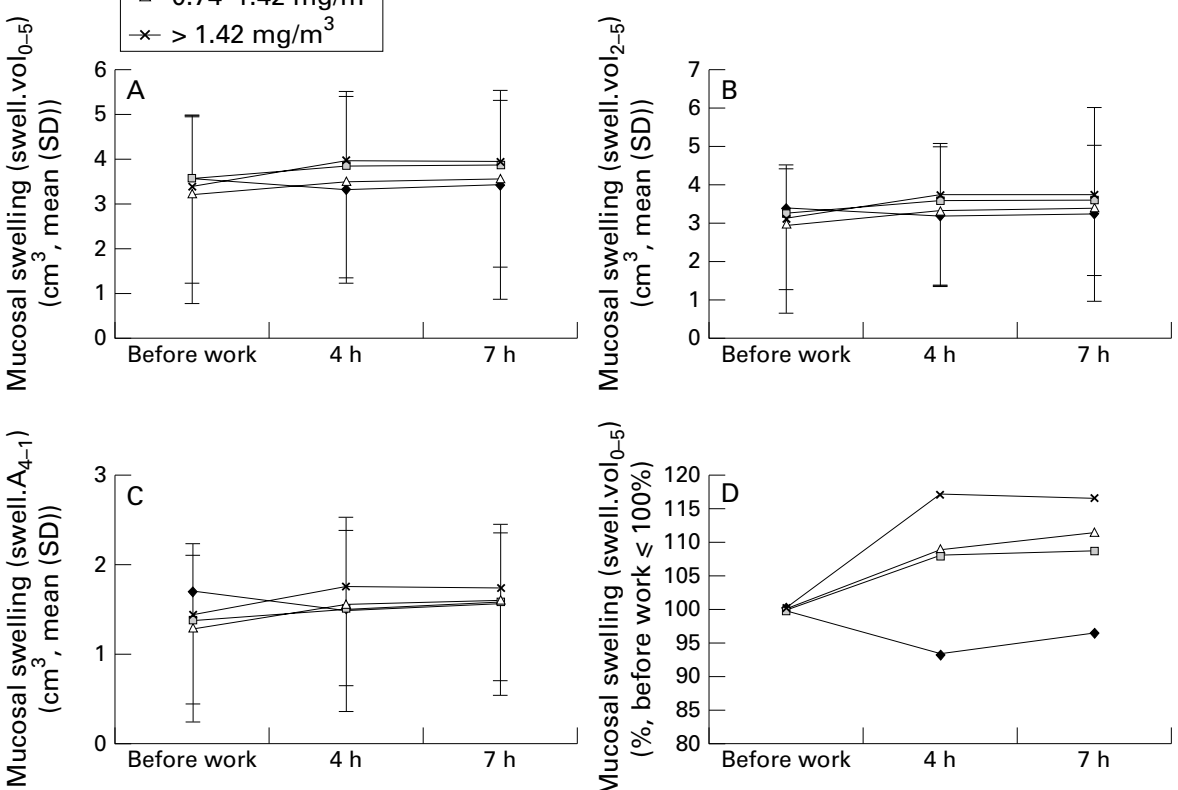

slightly increased, but at the expense of a slightly decreased precision (not shown).

Figure 2 shows the relation between $\operatorname{Dvol}_{2-5}$ and the concentration of inhalable dust including controls, where the controls were assigned $0 \mathrm{mg} / \mathrm{m}^{3}$ as their dust concentration. The linear regression was significant.

\section{Rating of symptoms}

Table 5 shows difference in self rated nasal obstruction (after work-before work) for the four exposure groups. A significant increase in nasal obstruction was found after work compared with before work for the two groups with the highest exposure. The same tendency was found for the group with low exposure, although non-significant. No significant difference was found across the four exposure groups, in the first or in the third measurement round (not shown).

Linear regression with self rated nasal obstruction in the four exposure groups showed a tendency toward greater difference with increasing dust concentration, although this was non-significant (coefficient $0.40, \mathrm{p}=0.112$ ).

Table 4 Linear regression of change in congestion between first and second measuring rounds and dust exposure (categorised in three exposure levels and no exposure; sum of right and left side values)

\begin{tabular}{|c|c|c|c|c|c|c|c|c|c|c|c|c|}
\hline & \multicolumn{3}{|l|}{$\mathrm{DA}_{\min } 1$} & \multicolumn{3}{|l|}{$\mathrm{DA}_{4.1}$} & \multicolumn{3}{|l|}{ Dvol $_{0-5}$} & \multicolumn{3}{|l|}{$\mathrm{Dvol}_{2-5}$} \\
\hline & Coef & St Coef & $\mathrm{p}$ Value & Coef & St Coef & $\mathrm{p}$ Value & Coef & St Coef & $\mathrm{p}$ Value & Coef & St Coef & $\mathrm{p}$ Value \\
\hline Dust exposure & 0.038 & 0.168 & 0.076 & 0.215 & 0.306 & 0.001 & 0.316 & 0.200 & 0.022 & 0.320 & 0.232 & 0.008 \\
\hline Height & $-\dagger$ & & & $-\dagger$ & & & 0.035 & 0.188 & 0.033 & 0.034 & 0.205 & 0.020 \\
\hline Heart rate before work & 0.023 & 0.161 & 0.001 & 0.009 & 0.205 & 0.022 & 0.026 & 0.254 & 0.004 & 0.022 & 0.253 & 0.004 \\
\hline Smoking* & -0.094 & -0.226 & 0.017 & -0.329 & -0.251 & 0.005 & -1.069 & -0.364 & 0.000 & -0.893 & -0.348 & 0.000 \\
\hline $\mathrm{R}^{2}$, complete model & 0.102 & & & 0.216 & & & 0.249 & & & 0.258 & & \\
\hline $\mathrm{R}^{2}$, only dust included $\neq$ & 0.007 & & & 0.073 & & & 0.037 & & & 0.048 & & \\
\hline
\end{tabular}

$\mathrm{DA}_{\min }=$ minimum cross sectional area; $\mathrm{DA}_{33}=$ cross sectional area at $3.3 \mathrm{~cm} ; \mathrm{DA}_{41}=$ cross sectional area $4.1 \mathrm{~cm} ; \mathrm{Dvol}_{0-5}=$ volume of the nasal cavity $0-5$; $\mathrm{Dvol}_{2-5}=$ volume of the nasal cavity $2-5 \mathrm{~cm}$ from the nostrils.

Coef=regression coefficient; St Coef=standard regression coefficient. * Non-smokers $=0$, smokers $=1$; $†$ Not included in the final model; $¥$ The coefficient in the model, where only dust were included, did not significantly differ from the dust exposure coefficient in the complete model.

Age, height, weight, pulse before the first and second measuring rounds, smoking, allergy, hay fever, temperature, use of compressed air and use of pine wood included in the original models, only significant confounders remain in the final models. 


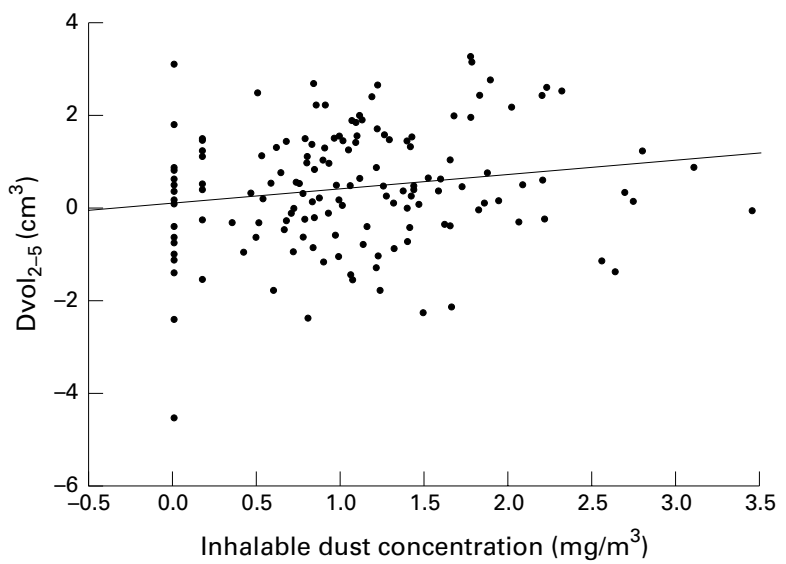

Figure 2 The relation between $\mathrm{Dvol}_{2-5}$ and the concentration of inhalable dust including controls, where the controls are assigned 0 $\mathrm{mg} / \mathrm{m}^{3}$ as their dust concentration. Linear regression line: Dvol $\left(\mathrm{cm}^{3}\right)=0.0958+0.33$ xexposure to dust $\left(\mathrm{mg} / \mathrm{m}^{3}\right), \mathrm{p}=0.025$; $R^{2}=0.034$

No significant correlation between absolute values for acoustic rhinometry variables and self rated nasal obstruction was found for either the total nose, or for the left and right side separately.

Additionally, no significant correlation between changes in acoustic rhinometry variables and change in self rated nasal obstruction during the day was found.

\section{DISCUSSION}

Our results indicate that exposure to wood dust is related to acute nasal obstruction. To our knowledge, this is the first epidemiological investigation applying acoustic rhinometry relative to wood dust concentration in the wood industry. One proposed mechanism for irritation is that wood dust inhibits normal mucuciliary clearance. ${ }^{26}{ }^{27}$ In studies of woodworkers, rhinoscopic examinations have shown abnormal mucous lining with a swollen, granular, or extremely dry mucosa, ${ }^{28}$ and evidence of inflammatory effects related to wood dust (increased albumin and neutrophil concentration) in the nasal mucosa has been reported. ${ }^{29}$

In this study, selection bias was less likely, as the participants were randomly chosen from the total study population. No significant differences were found between demographic characteristics of this randomly selected study population and the total study population for age (37 $v 37$ years) or men ( $88 \% v 82 \%)$. There was no obvious explanation for there being significantly less current smokers in the randomly selected population ( $33 \% v 42 \%)$. Recall bias due to an awareness of exposure may effect symptom reporting, but it is unlikely to affect clinical signs of nasal congestion. Age, sex, height, weight, smoking, hay fever, and allergic predisposition were controlled for without the results of the bivariate analysis being changed.

\section{Occupational hygiene survey}

The level of exposure among this subsample of people was nearly identical to the level in the total population, where the arithmetic mean (SD) for 1685 equivalent inhalable dust measurements was $1.19(0.86) \mathrm{mg} / \mathrm{m}^{3}$, range $0.17-9.78 \mathrm{mg} / \mathrm{m}^{3}$. This suggests that the random sampling of people has been successful.

The general concentration of wood dust was low, compared with earlier studies in the wood industry. ${ }^{20}$ The concentrations of dust have decreased during the past 25 years and a comparison between a Danish national cross sectional study in the wood and furniture industry in $1988^{31}$ and the present study showed a $52 \%$ decrease of dust exposure in the Danish furniture industry. ${ }^{32}$

Earlier studies which have investigated the relation between concentration of wood dust and respiratory health effects have mainly used the total dust sampling fraction. The rationale of sampling particle sizes of reference to expected health effects has gained more international attention..$^{334}$ Laboratory research and some practical field studies have shown that the inhalable dust fraction rather than total dust is more relevant to expected health effects from the upper part of the respiratory tract. ${ }^{2035-37}$ In this study, the equivalent inhalable dust fraction was chosen because effects on the upper part of the respiratory tract were investigated.

Woodworkers are intermittently exposed to other potential irritants, especially when using paints, lacquers, and glues. For that reason, people working with surface coating were excluded from the study population. The glue used in the factories participating in this study was mainly water based without formaldehyde, and the formaldehyde content in chipboard and fibreboard has declined substantially during the past 15 years (unpublished data). It is unlikely, that such exposures would have had a strong influence on the symptoms. However, interaction with wood dust and other irritants cannot be excluded.

Working with pine was included in the analysis, because earlier studies have indicated that the emission of the volatile organic compounds terpenes are important for irritative reactions in the upper airways. ${ }^{38-40}$ Working with pine dust did not in a significant way contribute to nasal patency and was excluded from the final model.

\section{Acoustic rhinometry}

Posture and breathing are known to affect the nasal patency measured by acoustic rhinometry, ${ }^{41}{ }^{42}$ and therefore the measurements were performed in a standardised way.

In this study, rhinometric variables for the anterior part of the nose were smaller among women than men, which agrees with a recent study from Sweden. ${ }^{43}$ On the contrary, Grymer et $a l^{22}$ found a tendency towards higher values for women. Comparing the three studies, the values for men were in the same range, but the values for women were higher in the study by Grymer et al.

The unequal distribution of men and women among exposed and controls in this study tend to underestimate the rhinometric variables in the control group, especially, $\mathrm{A}_{\text {min }}$, $\mathrm{vol}_{0-5}$, and $\mathrm{vol}_{0-7}$. The results indicate no difference in nasal patency between the control group and the three exposed groups for the three measurement rounds separately. Reference values for acoustic rhinometry show wide variations in nasal variables between people and suggest that the method is most reliable for comparisons within individual people. ${ }^{22} 43$ Also, a

Table 5 Difference in nasal obstruction (after work-before work) measured on a VAS scale, medians (range) for four exposure groups

\begin{tabular}{lllll}
\hline & $\begin{array}{l}\text { Controls } \\
\mathrm{n}=18\end{array}$ & $\begin{array}{l}\text { Low exposure } \\
\left(0.17-0.74 \mathrm{mg} / \mathrm{m}^{3}\right) \\
\mathrm{n}=30\end{array}$ & $\begin{array}{l}\text { Medium exposure } \\
\left(0.74-1.42 \mathrm{mg} / \mathrm{m}^{3}\right) \\
\mathrm{n}=72\end{array}$ & $\begin{array}{l}\text { High exposure }(1.42 \\
\left.\mathrm{mg} / \mathrm{m}^{3}\right) \\
\mathrm{n}=36\end{array}$ \\
\hline Nasal obstruction (after work -before work) & $-0.18(-8.40,-9.25)$ & $0.15(-4.80,-6.60)$ & $0.60(-8.90,7.75)^{*}$ & $0.63(-10.00,-7.70)^{*}$ \\
\hline
\end{tabular}

${ }^{*} p<0.05$, nasal obstruction after work compared with nasal obstruction before work. Wilcoxon signed rank test for paired data. 
cross sectional design is not ideal to investigate chronic health effects, and may have caused an underestimation of the true effect if there was any health based selection away from the furniture industry.

Exposure to wood dust was positively related to a dose-dependent change in mucosal swelling between first and second measuring round. The results were consistent across the different variables, which is not surprising, as the variables by nature are highly correlated. The nasal effect was most marked after 4 hours of work, and was not further increased during the rest of the working day, indicating that an upper limit is reached within a few hours. By contrast, smoking was negatively correlated with change in the measured nasal variables. Smokers had less increase in mucosal swelling than non-smokers between the first and second measuring round.

The difference was due to a greater tendency in smokers than non-smokers to increased mucosal swelling in the first measuring round and decreased mucosal swelling in the second measuring round. One explanation may be an increased baseline mucosal swelling and a decreased mucosal reactivity among smokers due to a congestant effect of smoking. ${ }^{44}$

Heart rate before the first measuring round was slightly but significantly positively related to change in mucosal swelling. Further analysis showed a positive relation between change in heart rate and change in mucosal swelling between the first and second measuring round (not shown). The influence of exercise on the nasal mucosa is well known. ${ }^{45}$ Heart rate in this study is measured as a proxy for the level of physical activity. A high level of physical activity before the first measuring round will tend to decrease mucosal swelling due to increased sympatic tone at the first measurement leading to a greater potential swelling in the following period of time.

The mean (SD) heart rate was significantly higher before the first than the second measuring round $(79.3$ (14.2) $v 73.9$ (13.1), p<0.001). The first measuring round was not consistently preceded by a 15 minute resting period, by contrast with the last three measuring rounds. This may explain the higher heart rate before work, and underline the importance of taking the physical activity level into consideration in the analyses.

Height was slightly but significantly positively related to change in the volume variables of mucosal swelling between the first and second measuring round. In another study of 106 adults no significant relation to height was found, but in a different study that included children, $\mathrm{A}_{\min }$ was positively related to height and weight, ${ }^{43}$ which probably reflected a natural relation between nose dimensions and body size.

Temperature is known to affect the nasal patency, ${ }^{16}{ }^{46}$ and an interaction between temperature and exposure on volume of the nasal cavity has been documented. ${ }^{46}$ Temperature was therefore included in the initial model, but did not contribute in a significant manner; hence, it was excluded from the final model. It must be emphasised, that the mean room temperature is a crude measure for the temperature.

Use of compressed air, as a proxy for high dust peak concentrations, was excluded in the final model, as it did not contribute in a significant manner to the model.

As shown by the $R^{2}$ values in table 4 , smoking, heart rate, and to a lesser extent height are important explanatory variables for change in nasal patency, compared with wood dust, highlighting the importance of taking alternative explanations into consideration in the interpretations of the results.

The humidity was not measured in this study. The humidity at furniture factories is fairly constant $(40 \%-50 \%$ relative humidity) to keep the water content in the wood constant (personal communication). In an experimental study of eight people, Pedersen et al did not find any effect of humidity on the nasal patency measured by acoustic rhinometry, with relative humidity ranging from $15 \%$ to $85 \%$ (unpublished data).

\section{Key messages}

- Exposure to wood dust was related by dose to acute nasal obstruction measured by acoustic rhinometry and by self reported obstruction.

- Smoking, heart rate, and height were also related to nasal patency.

- No correlation was found between self reported obstruction and nasal patency measured by acoustic rhinometry.

\section{Rating of symptoms}

The visual analogue scale has been considered most suitable for rating symptoms within individual people, ${ }^{47}$ thus the paired comparisons between first and third measuring round are probably more valid than the comparisons within individual people between the four exposure groups.

The positive relation between woodworkers with medium and high exposure and increase in self reported nasal obstruction before and after work indicate an acute dosedependent effect of wood dust on nasal obstruction. In a study by Åhman et al ${ }^{3}$ woodwork teachers rated more nasal obstruction (on a visual analogue scale) on Tuesday afternoon than on Monday morning.

No significant correlation between acoustic rhinometry variables and the feeling of obstruction in both nostrils was found, which agrees with earlier studies. ${ }^{48}{ }^{49}$ Although, Roithmann et $a l^{48}$ found a relation between ipsilateral $\mathrm{A}_{\min }$ and subjective obstruction, which could not be confirmed in this study, Grymer et $a l^{50}$ found weak correlation between subjective obstruction and $\mathrm{A}_{\min }$ for the narrow side of the nose. Although some subjects might feel congested due to a unilateral obstruction, it seems most relevant from a clinical point of view to investigate the sum of values from the two nostrils.

In conclusion we have shown that a dose dependent exposure to wood dust is related to acute nasal obstruction measured by acoustic rhinometry and by self reported obstruction, but no correlation between acoustic rhinometry and self reported obstruction was found.

\section{ACKNOWLEDGEMENTS}

This work has been supported by the Danish Work Environment Foundation, Viborg County, the Danish Medical Research Council, the Wood Industry and Building Workers Union in Denmark, the Danish Lung Association, the Asthma and Allergy Association, and the Health Insurance Fund.

\section{Authors' affiliations}

V Schlünssen, I Schaumburg, N T Andersen, Department of Occupational and Environmental Medicine, Skive Hospital, DK 7800, Skive, Denmark

T Sigsgaard, O F Pedersen, Department of Environmental and Occupational Medicine, University of Aarhus, DK 8000, Aarhus C, Denmark

\section{REFERENCES}

1 Ramazzini B. Diseases of workers, the Latin text of 1713. ChicagoIllinois: The University of Chicago press; 1940.

2 International agency for research on cancer. IARC monographs on the evaluation of carcinogenic risks to humans. Vol 62. Wood dust and formaldehyde. Lyon: International Agency for Research on Cancer, 1995.

3 Åhman M, Holmstrom M, Cynkier I, et al. Work related impairment of nasal function in Swedish woodwork teachers. Occup Environ Med 1996;53:112-7.

4 Wilhelmsson B, Drettner B. Nasal problems in wood furniture workers. A study of symptoms and physiological variables. Acta Otolaryngol Stockh 1984:98:548-55.

5 Mandryk J, Alwais KU, Hocking AD. Work-related symptoms and dose-response relationships for personal exposures and pulmonary function among woodworkers. Am J Ind Med 1999;35:481-90.

6 Åhman M, Söderman E, Cynkier I, et al. Work related respiratory problems in industrial arts teachers. Int Arch Occup Environ Health 1995;67:111-8. 
7 Shamssain $\mathbf{M H}$. Pulmonary function and symptoms in workers exposed to wood dust. Thorax 1992;47:84-7.

8 Norrish AE, Beasley R, Hodgkinson EJ, et al. A study of New Zealand wood workers: exposure to wood dust, respiratory symptoms, and suspected cases of occupational asthma. New Zealand Medical Journal 1992;105: 185-7.

9 Ruppe K. Diseases and functional disorders of the respiratory tract in workmen of the wood processing industry. CA Cancer J Clin 1973;23:261-4. (In German.)

10 Pisaniello DL, Connell KE, Muriale L. Wood dust exposure during furniture manufacture: results from an Australian survey and considerations for threshold limit value development. Am Ind Hyg Assoc J 1991;52:485-92.

11 Solgaard J, Andersen I. Lung function and symptoms among woodworkers. Ugeskr Læger 1975;137:2593-9. (In Danish.)

12 Hilberg $\mathrm{O}$, Jackson AC, Swift DL, et al. Acoustic rhinometry: evaluation of nasal cavity geometry by acoustic reflection. J Appl Physiol 1989;66:295-303

13 Wålinder, R. Nasal reactions and the school environment [thesis] Uppsala, Sweden: Uppsala University, 1999.

14 Fischer EW. Acoustic rhinometry. Clin Otolaryngol 1997;22:307-17.

15 Wålinder R, Norback D, Wieslander G, et al. Nasal patency and lavage biomarkers in relation to settled dust and cleaning routines in schools. Scand J Work Environ Health 1999;25:137-43.

16 Mølhave L, Liu Z, Jørgensen AH, et al. Sensory and physiological effects on humans of combined exposures to air temperatures and volatile organic compounds. Indoor Air 1993;3:155-69.

17 Schlünssen V, Schaumburg I, Taudorf E, et al. Respiratory symptoms and lung function among Danish woodworkers 2000. J Occup Environ Med 2001 (in press).

18 Vinzents PS. A passive personal dust monitor. Ann Occup Hyg 1996;40:261-80.

19 Vinzents, P.S. Assessment of occupational exposure to dust and other selected air pollutants based on measurements in large study population [thesis]. Copenhagen: Department of Occupational Hygiene / National Institute of Occupational Health, Denmark, 1996.

20 Mark D, Vincent JH. A new personal sampler for airborne total dust in workplaces. Ann Occup Hyg 1986;30:89-102.

21 Arbejdstilsynet (Danish Working Environment Service) Grænseværdier for stoffer og materialer. At-anvisning Nr. 3.1.0.2. Copenhagen: Arbejdstilsynet, 1994. (In Danish.)

22 Grymer LF, Hilberg O, Pedersen OF, et al. Acoustic rhinometry: values from adults with subjective normal nasal patency. Rhinology 1991;29:35-47.

23 Maxwell C. Sensitivity and accuracy of the visual analogue scale: a psycho- physical classroom experiment. Br J Clin Pharmacol 1978;6:15-24

24 British Medical Research Council Committee on the aetiology of chronic bronchitis. Definition and classification of chronic Bronchitis for clinical and epidemiological purposes. Lancet 1965;i:775-9.

25 Sigsgaard T, Hiort C, Omland $\varnothing$, et al. Respiratory health and allergy among young farmers and non-farming rural males in Denmark: The SUS study. Journal of Agro Medicine 1997;4:63-78.

26 Black A, Evans JC, Hadfield EH, et al. Impairment of nasal mucociliary clearance in woodworkers in the furniture industry. $\mathrm{Br} J$ Ind Med 1974;31:10-7.

27 Andersen HC, Solgaard J, Andersen I. Nasal cancer and nasal mucus-transport rates in woodworkers. Acta Otolaryngol Stockh 1976;82:263-5

28 Wilhelmsson B, Lund B. Nasal epithelium in woodworkers in the furniture industry. A histological and cytological study. Acta Otolaryngol Stockh 1984;98:321-34.
29 Åhman $M$, Holmstrom $M$, Ingelman-Sundberg $H$. Inflammatory markers in nasal lavage fluid from industrial arts teachers. Am J Ind Med 1995;28:541-50.

30 Demers PA, Teschke K, Kennedy SM. What to do about softwood? A review of respiratory effects and recommendations regarding exposure limits. Am J Ind Med 1997;31:385-98.

31 Vinzents PS, Laursen B. A national cross sectional study of the working environment in the Danish wood and furniture industry: air pollution and noise. Ann Occup Hyg 1993;37:25-34.

32 Schlünssen V, Vinzents PS, Mikkelsen AB, et al. Wood dust exposure in the Danish furniture industry. Ann Occup Hyg 2001;45:157-64.

33 European Committee for Standardisation. Workplace atmospheres: size fraction. Definitions for measurement of airborne particles. Brussels: European Committee for Standardisation. 1993. (EN 481.)

34 International Organisation for Standardisation and Dansk Standard. International Organisation for Standardisation, air quality-size fraction. Definitions for health-related sampling. Geneva: IOS, 1995. (ISO 7708.)

35 Hinds WC. Basis for particle size-selective sampling for wood dust. Appl Ind Hyg 1988;3:67-72.

36 Mark D, Lyons CP, Upton SL, et al. Wind tunnel testing of the sampling efficiency of personal inhalable aerosol samplers. J Aerosol Sci 1994:25:S339-40.

37 Vincent JH, Mark D. Entry characteristics of practical workplace aerosol samplers in relation to ISO recommendations. Ann Occup Hyg 1990;34:249-62.

38 Dahlqvist $M$, Palmberg L, Bergstrom B, et al. Acute exposure for air pollution in a saw mill among healthy volunteers. Arbete och Hälse 1996;10:1-11. (In Swedish.)

39 Falk AA, Hagberg MT, Lof AE, et al. Uptake, distribution and elimination of alpha-pinene in man after exposure by inhalation. Scand J Work Environ Health 1990;16:372-8.

40 Falk A, Löf A, Hagberg $M$, et al. Human exposure to 3-carene by inhalation: toxicokinetics effects on pulmonary function and occurrence of irritative and CNS symptoms. Toxicol Appl Pharmacol $1991 ; 110: 198-205$.

41 Kase $Y$, Hilberg $O$, Pedersen OF. Posture and nasal patency: evaluation by acoustic rhinometry. Acta Otolaryngol Stockh 1994;114:70-4.

42 Tomkinson A, Eccles R. Errors in cross-sectional area estimation by acoustic rhinometry produced by breathing during measurements. Rhinology 1995;33:138-40.

43 Millqvist E, Bende M. Reference values for acoustic rhinometry in subjects without nasal symptoms. Am J Rhinol 1998;12:341-3.

44 Bascom R, Kesavanathan J, Permutt T, et al. Tobacco smoke and upper respiratory response relations in healthy non-smokers. Fundam Appl Toxicol 1996;29:86-93.

45 Hilberg O, Grymer LF, Pedersen OF. Spontaneous variations in congestion of the nasal mucosa. Ann Allergy Asthma Immunol 1995;74:516-21.

46 Lundqvist GR, Pedersen OF, Hilberg O, et al. Nasal reaction to changes in whole body temperature. Acta Otolaryngol Stockh 1993;113:783-8

47 Stark RD. Dyspnoea: assessment and pharmacological manipulation. Eur Respir J 1988;1:280-7.

48 Roithmann R, Cole P, Chapnik J, et al. Acoustic rhinometry, rhinomanometry, and the sensation of nasal patency: a correlation study. J Otolaryngol 1994;23:454-8.

$49 \mathrm{Kim}$ CS, Moon BK, Jung DH, et al. Correlation between nasal obstruction symptoms and objective parameters of acoustic rhinometry and rhinomanometry. Auris Nasus Larynx 1998:25:48.

50 Grymer LF, Hilberg O, Pedersen OF. Prediction of nasal obstruction based on clinical examination and acoustic rhinometry. Rhinology 1997;35:53-7. 